\title{
Effect of a Training Program on the Development of Writing Skills Among Special Education Students
}

\author{
Dr. Aiman Mohammd Ahmad Freihat \\ Department of Educational Sciences, Ajloun College, AL-Balqa Applied University, Ajloun 26816, Jordan
}

\begin{abstract}
The present study aimed to build a training program and knowing its effect on developing the writing skills of special education students. The study sample consisted of (12) students in the fourth year in the specialty of special education. The researcher used the experimental design of one group, a note form was used to measure the writing skill. The instrument was verified by presenting it to a group of competent arbitrators, but the Reliability was calculated in a way that the observers Reliability. A second observer was trained on the use of the two forms, and then the ratio of the agreement between the observers was found. The final form of the writing skill consisted of (16) paragraphs, and the training program consists of two parts: The first part included the theoretical content of the writing skill while the second part included the practical training of the skill using the mini-teaching technique to train the applying students. The results showed that there are no statistically significant differences between the post and field tests for writing skills because the averages were close.
\end{abstract}

DOI: $10.7176 / \mathrm{JEP} / 10-11-09$

Publication date: April $30^{\text {th }} 2019$

\section{Introduction}

From time to time, there is a growing demand to reform the education system so that this system is compatible with the scientific and technological developments in the world that leave their mark on different sectors of life.Including the education sector, which requires the need to keep pace with the programs of teachers preparation for scientific developments and assimilation of the necessary skills that help the teachers to teach professionally to perform their new roles has led to the trends and innovations of education that the educators have been calling in recent times as the role of the teacher has changed and exceeded the traditional boundaries, it requires that the preparation programs before and during the service programs that provide expertise and teaching methods and all that earns the teacher teaching skills commensurate with this role and the requirements of modern developments in the objectives of education and its content and methods and sources (Al Rusan, 2004).

It is no secret that the preparation of a good teacher is a commitment to the youth and to the level of the profession of education, in addition to the emergence of new skills of teaching linked to the use of educational techniques lead us to review the programs of teacher preparation from time to time. To enable teachers before their involvement in the profession to master those skills and competencies that have become necessary to use because it helps them to provide important explanations for students and to stimulate learning.

\section{Research problem:}

Through my presence as a field training supervisor for special education students, I found that there is a problem in some of the teaching skills used by students, including writing skills, which is one of the basic and main skills that students use at schools being the target group who are disabled with learning. Specifically, this study came to answer the following questions:

-There is no statistically significant difference between the average of the pre-test and post-test scores in the performance of the research group for writing skill.

-There is no statistically significant difference between the average of the post-test and the field tests in the performance of the research group for writing skill.

\section{Research importance}

The importance of this research can be crystallized by:

1. Building a training program for special education students to develop writing skills, which are basic skills necessary for the preparation of teachers of special education.

2. It provides the colleges of education, especially the special education departments, with a new methodology in preparing their students for the teaching profession.

3. The Directorate of Education may benefit from the adoption of the training program as part of the in-service vocational training programs for its teachers.

\section{Research goals:}

1-Building a training program in developing writing skills among special education students. 
2-To recognize the impact of the training program in developing the writing skills of special education students.

\section{Search limits}

1-Students of the fourth year in the Department of Special Education at Ajloun University College / Balqa Applied University

2- The classroom in the Department of Special Education. In Ajloun University College / Balqa Applied University.

\section{Search terms}

\section{1- Training Program:}

A set of planned and organized activities to help trainees to improve their efficiency and improve their classroom performance.

\section{2- Writing skill:}

All mechanical acts performed by the student / teacher and necessary to draw letters and words clearly for the purpose of teaching students through mastery of the skill of writing through the research tool prepared by the researcher.

\section{3- Special Education:}

The total of specialized educational programs offered to groups of extraordinary individuals in order to help them to develop their abilities to the most possible extent and achieve themselves and help them to cope up with.

\section{Theoretical framework and previous studies \\ First, the theoretical framework.}

\section{3- Special Education:}

Special education is a modern subject in the field of education and the organized beginnings of this subject go back to the second half of the last century. The subject of special education combines a number of sciences from the fields of psychology, education and sociology. The subject of special education deals with individuals who differ from ordinary individuals in their mental, sensory, emotional, motor and linguistic development. This requires special attention by educators in these individuals in terms of their diagnosis and Their educational programs. (Rousan, 20014).

\section{- *Objectives of special education:}

The objectives of special education have varied according to the educators and those interested in this field. It should not be forgotten that the special education classes are not a single class. There are differences among them that need to be studied and special educational goals that vary according to the nature of those needs.

The goal of special education is to provide services to the special student in order to create the right conditions for him to grow properly and achieve himself by achieving his potential and development to the maximum level that can reach him and to recognize the services he accepts in an atmosphere of love and sensations. (Abbadi, 20014).

- *Special education strategies:

The strategy of teaching for special education students requires taking two important aspects. The first is to adopt the strategy in the individual way, that is to build each student a program of his own so-called strategies of individual teaching for each student. The second is to set goals after measuring the current level of performance, A strategy to teach.

Special education strategies are::

\section{A - Method of training on operations:}

In this way, the teaching plan is designed to treat the functions of processes that suffer from weakness or atrophy in the child. For example, if the child has a reading problem as a result of weak auditory skills in this case, the child may be given training in distinguishing between one of the voices and another voice. The first is that this skill continues to grow and develop and thus facilitate the assessment of the overall skills of listening and reading later (Al Rousan2014).

\section{B - Method of analysis of educational homework:}

The method of analysis of educational duty as a method of treatment requires careful identification and clear understanding of all the partial steps required to learn any homework (Rusan, 2014).

C - Combining the methods of training in processes and analysis of home works:

The vast majority of children benefit from educational strategies that combine the advantages of the two previous methods. The resulting method includes the advantages of operational training and the advantages of analyzing the educational homework in one therapeutic program. This means that the child learns how to use a specific process to do the desired job.

Under this method, a child may have difficulty distinguishing geometric shapes. This cognitive problem may result in the child having difficult in distinguishing alphabetic forms. In this case, remedial efforts should 
aim to teach children more about the forms of letters than to teach them geometric forms in themselves as long as character recognition is the immediate and ultimate objective (Abd al-Rahim, 1990).

* - The stages of the process of teaching writing:

1 - Preparation for writing and it represents in preparing exercises for the preparation of the student to write as it provides the student with the following:

First: the definition of writing tools.

Second: Accustom to keeping the pen and correcting the wrong situation.

Third, the right direction to write from right to left.

Fourth, he should recite the correct session.

Fifth: Exercise his muscles and his hand to keep up with the eye.

Sixth: the adaptation of some values and skills such as cleanliness and order and follow the lines.

2- Writing: in this stage brochures are for writing as the teacher to teach students to write according to the following steps:

First: The teacher reads the sentence to be written and then asks a number of students to read it.

Second: The teacher refers to the intended letter and pronounces it, and then the pupils imitate him.-

Third: the teacher points to the arrows to explain to the pupils the steps of writing the letter in capital using his finger or cursor, and then write the letter on the blackboard slowly asking them to follow him.

Fourth: The teacher then moves to the writing exercises and explains the instructions to write over the point and write without points with the starting point and write the letter or section within the word and write sections, words and sentences.

* - Writing difficulties and the treatment:

It is a disturbance of the effort of vision and movement. A child or a person with writing difficulties cannot pass information through the sense of sight to the motor system and this is shown clearly .(AbdaLhadi and others, 2000).

The most important appearances of these difficulties are:

1 - Reversing writing letters to be as they look in the mirror or reversing writing words and sentences.

2 - Confusion or mixing up in directions so he may begin to write words and sections from the left instead of writing them from the right.

3 - Arranging the words or letters incorrectly.

4 - mixing up in writing between similar letters.

5 - Drawing the letters wrongly.

6 - Holding the pen in the wrong way.

7 - Neglecting points on the letters.

There are a number of strategies to address the writing difficulties mentioned above, notably:

The first strategy: Separate copies of the expression.

We need as teachers to appreciate the writing process with all the complexities involved, it is not a copy process for written pieces free of mistakes. But they are real ideas for children expressed themselves in writing and so we have to encourage them regardless of the form taken by their writings, spelling, coherence and punctuation and so on will be interested later on, children need to write without fear of making mistakes.

The second strategy: teaching the language as a skill, not rules:

It is important to know the language as a skill, not as rules and laws. Knowledge of rules alone is not enough for the writing process. What students need is to use these rules in their writings through permanent and regular practice (Melhem, 2002).

The third strategy: Respecting intelligence behind mistakes:

As teachers, we have to analyze the mistakes in student writing, first to identify the reasons behind these mistakes and secondly the appropriate methods of addressing them and without allowing students to write freely. These mistakes remain unknown and there will be no treatment or development of the writing process of these students.

The fourth strategy : Trusting in automatic or accidental learning:

When the student practices the process of writing daily, then he develops his writing experiences and when his colleagues and teacher participate in these productions, then he creates what is called the imaginary writer circle, just as it is formed for the writers and the great authors. (Rousan, 2001).

\section{Second: Previous Studies:}

\section{1- Ahmad study (1989)}

The study aims at shedding light on some aspects of the program of preparing the teacher of special education and its components. The study has reached to develop a proposed model for a special program for preparing the teacher of special education and training, explaining the basis for planning this kind of programs, the prevailing trends in this field and the criteria on which it is based on its evaluation, with the presentation of a complete model that can be followed to prepare and train special education teachers in the Arab world. 
2-Ahmed Wadoha study (1992) (training needs and priorities for teachers and special education teachers in the State of Qatar) This study aims at monitoring and assessing the training needs of special education teachers in Qatar as felt by these teachers. The study sample consisted of (64) teachers. During the study, the researchers used a questionnaire to measure the training needs and determine their priorities within ten main areas of training of the special education teacher. Each field included three sub-fields. The questionnaire included 30 training needs. The results of the study were the following:

- Indicates that the sample as a whole needs a high training process.

There was a great deal of agreement among the sample groups on the order of importance of priorities between the teachers of intellectual education and the teachers of audio education, since the coefficient of correlation between grades was not statistically significant.

- The need to pay attention to the training and rehabilitation of teachers of extraordinary students.

- Follow what is known as the entrance to training and competency-based training to identify the teaching competencies necessary for the teacher so that the design of training programs in light of these competencies.

- The teacher is one of the most important sources of monitoring and assessment of teaching needs.

- Giving attention to providing programs for the preparation and training of special education teachers within the programs offered by the Faculty of Education at the University of Qatar to prepare qualified national cadres in the field of special education.

3- Haroon study (1995):(Survey of the students of the Department of Special Education at King Saud University on the degree of their acquisition of the teaching competencies necessary to teach people with special needs in regular schools). The study aimed at investigating the degree of acquisition of students of the special education department for the competencies necessary to teach special needs students in regular schools using the list of competencies. Using Landers \&Weavers lists (1991) to identify the competencies needed to prepare the pre-service educational integration teacher. The study results showed that special education students need these competencies that enable them to work effectively among students with disabilities within regular schools.

4- Smadi and Tayseer study (2001) (level of proficiency of teachers of special education in the United Arab Emirates for skills of effective education) This study aimed to assess the extent of proficiency of teachers of special education in the United Arab Emirates for effective teaching skills and the difference in the level of mastery of these skills according to gender and qualifications and experience in education.

\section{Al Bataineh study (2004):}

The results of the study showed that the degree of educational competencies of children with special needs that teachers possess, were high or medium. The results also showed statistically significant differences in educational competencies due to specialization, teaching experience and scientific qualification. While the results did not reveal statistically significant differences in educational competencies due to the gender variable.-

1- Schifoni\& others, 1975) study

"A survey of opinion on the training of teacher of Exceptional children "

The study aimed at monitoring the training needs of some of the training skills of special education teachers. The study also aimed to identify the training skills that were actually practiced. The study sample consisted of (120) teachers in special education field.

To achieve this objective, an expanded questionnaire was used for the training needs. The questionnaire also included the requirement of the teachers to determine the skills they practice and the degree of practice if they are actually practicing. If they do not practice, they have to clarify their degree of importance from their point of view. For the teacher of special education to benefit the design of training and preparation programs and the use of the entrance of competencies is commonly used.

\section{3- (Chang, 1985) study}

"Effective programming for student teachers in special Education"

The study was conducted in one of the institutes of higher education for teachers in the United States. The study aimed to provide an effective program for the preparation of students / teachers in special education and focused on the program suggested by the training of students / teachers on the various teaching skills, either through complex teaching positions or through real situations.

The study sample consisted of (45) students. The study recommended not to fill the program with many theoretical decisions to prove the futility or ineffectiveness of such courses after the teacher graduated for the level of his performance while stressing the importance of practical practice of the trainee student in providing real lessons in the field.

\section{Search procedures}

First: The research community and its sample:

The research community consists of (12) students in the fourth year / special education department in Ajloun College at Al Balqa University for the academic year (2017-2018). Due to the small number of them, the whole society was counted as a sample for the research.. 
Table1

Search community and sample1

\begin{tabular}{|c|c|c|c|}
\hline Experimental group & Males & Females & Total \\
\hline & 9 & 3 & 12 \\
\hline
\end{tabular}

Second: Experimental Design:

The experimental method has been adopted and is one of the most rigorous educational research methods, perhaps the most difficult and complex. It is also the most efficient means of reaching a reliable knowledge. This method can determine the effectiveness of the training program designed to develop some of the teaching skills of special education students. In order to achieve this, the researcher resorted to the design of the group as there is no better control than the use of the same group in both cases. The independent variables associated with the characteristics of the group members and the effect in the dependent variable have been controlled and one group is going through two situations, one is controlling the other (Odeh, 2012).

Given the small number of members of the research community, the researcher had no choice but to choose one group design. Figure (1) below shows the design of the research.

\section{Form 1}

The research experimental design

\begin{tabular}{|l|l|l|l|}
\hline Pre -test & Training program The independent variable & Post test & Differences \\
\hline
\end{tabular}

Secondly: Study variables:

1 - Independent variable (training program).

2-dependent variable: the performance of students on the skill of writing).

Third: Research Tools:

\section{Observation form:}

The researcher prepared anobservation form for writing skills. The researcher relied on preparing the observation form on a number of sources and literature related to teaching skills and special education and interviewing some specialists in the field of special education to poll their views on the skill of writing.

The questionnaire was presented in preliminary form to the committee of arbitrators to ascertain the validity of its scientific material and its suitability to the level of the students in the sample. Their views showed the validity of the questionnaire and some minor modifications were made to it. Note that the quintile was the five levels (performed very poorly, poorly performed, performed moderately, performed well, performed very well) and scores $(5,4,3,2,1)$ were assigned to the five levels, respectively.

2..Honesty2

The honesty of the test is defined as the accuracy with which the test measures the purpose for which the test was conducted (Alzaher and others, 2002). In order to verify the validity of the tool, the researcher used the virtual truth, which is one of the requirements of building the measure to be measured (Freeman, 1962, p.90). The researcher presented the form of observation prepared by the arbitrators committee and asked them to study the components of writing skill and to express opinion. In light of the arbitrators' opinions, four components of the note form were deleted. The researcher continued to accept each component in the case of achieving the proportion of the agreement of the arbitrators $(80 \%)$ and more. Bloom pointed out that if the component obtained the proportion of agreement (75\%) and more, the test is honest (Bloom and others, 1983).

3.Stability: Stability is defined as accuracy of measurement or stability of results. There is more than one way to calculate the stability of the observation system and the method ofobservers agreement in calculating the stability of the most common methods. Therefore, the presence of one observer at least in addition to the first observer (researcher) to observe the teaching of the same teacher and at the same time using the observation system to find stability after the observers recorded the performance of five teachers in five lessons in reading and five lessons in another article (Odeh, 2012).

They were randomly selected at the Ezz El Din Usama Primary School. The two observers entered the class at the beginning of the lesson and one of them sat in one corner and the other in another corner, this means that each one works individually. They started observing the teacher's performance inside the class. And then the researcher to collect forms of observation for each of the first observer (researcher) and the second observer and extract the proportions of agreement and disagreement between observers..

Fourth: Training Program:

After the researcher learned a number of sources and literature about the training programs, I found that there are three stages through which the training programs are first design, second implementation, third evaluation. Here is a clarification of each stage.

1. The design phase of the training program includes:

A - Identification of teaching skills:

After reviewing a number of sources, references and literature and through the experience of the researcher as well as the discussion of a number of specialists and arbitrators within the specialty of special education, the researcher determined the skill of writing. 


\section{B. The overall objective of the program:}

The training program aims at using the students / trainees to use the mini-teaching technique to develop writing skills.

\section{Behavioral objectives of the program:}

The behavioral goals of the writing skill were formulated in a specific, short and expressive manner to measure and indicate the behavior of students / trainees.

A special form was prepared for the behavioral goals of the writing skill, which included the form of writing skill (16) paragraph (behavioral goal)

\section{The theoretical content of the program:}

The vocabulary of the theoretical content of the program included the following:

- A general idea of mini-teaching.

- Steps to implement the mini-teaching.

Writing skill.

E. Selection of training technology:

The training program adopted the mini-teaching technique in training students / trainees to develop the skill of writing and he uses the mini teaching. The colleagues play

the role of students due to its difficult to have real students as well as the participation of colleagues in assessing the performance of the student / teacher.

After the researcher acquainted with a number of literature and in its light the steps of the mini-teaching technology were identified that will be followed in the implementation of the training program as follows:

1- The researcher should give a theoretical presentation about the skill required for training.

2 - The researcher provides a model lesson and discusses with students and answer questions about skill.

3. Each student/applicant should plan a mini-course on a topic.

4 - Each Student / Applicant should present for a short lesson (5-10) minutes for a specific number of students / colleagues ranging from (8-12) students and the lesson is recorded on a video tape.

5 - Students/applicants should be provided by feedback through the presentation of the lesson recorded and the discussion with the student / applicants and guidance researcher as well as students / colleagues.

6 - Student / applied should replan for a mini-lesson in light of the feedback information received from the researcher and colleagues and re-teaching the skill again and provide feedback back to him through the video recording of the mini-lesson.

\section{F- Trainers and lecturers:}

To ensure the teaching and training process of the program, the researcher supervised the process of teaching and training of students of the experimental group using an instructor of educational psychology material.

\section{G- Duration of Program:}

The researcher divided the time of application of the training program of the experimental group on two following parts, the first to study the theoretical content, followed directly by the practical training of writing skills and can be illustrated as follows:

\section{1 - Study of theoretical content.}

The researcher devoted two hours to the theoretical content of writing skills.

\section{Practical Training.}

The researcher identified the period of implementation of the training program in the first semester of the academic year (2017-2018).

pre-test:

The researcher conducted a pre-test for the students of the experimental group through the request of each student to prepare two lessons, the first lesson is in reading and writing and the second lesson is in any material chosen by the student and after submission to the teachers, the researcher recorded their performance through the observation forms of writing skills. As well as the researcher to videotaped the lessons provided by the students by the camera in order to observe their performance and evaluate in light of the forms of observation.

\section{Implementation phase of the training program:}

The researcher carried out the implementation of the training program for the experimental group as follows: The students of this group underwent a mini-teaching program of 12 students / trainees. The researcher met with the students of the group for two hours a week for the purpose of explaining the skill and its sub-components to students / trainees. The researcher followed the steps of the mini-teaching six, namely the definition of the students of the theoretical content of the skill required to be trained and then presented a typical lesson for the components of the skill. Each student then planned and taught and recorded the lesson on a video tape and then received feedback and in light of which the students re-planning and re-teaching and then received feedback for the second time.

The course of the mini-training program has been defined as follows:

1. Each student (as homework) reads the part of the booklet on the components of the training stage to be trained. 
2 - The researcher presented a typical lesson for the components of writing skills and for all students of the group (12) students with a commentary on the components and discussion of students. At the end of the session, the researcher asked each student to plan a mini-lecture session for a short lesson (5-7 minutes) in which the components of the writing skill would be practiced and the lesson would be in one of the topics of reading and writing.

3 - Each student / student to submit his mini-lesson for students / colleagues from the mini-seminar and the lesson was recorded on a video tape. After the student has completed his / her course, he / she will take the role of the student / student so that another student can submit his / her mini-course and so on until the students of the group complete.

4 - After the completion of the introduction of mini-lessons by the students of the whole group received each student feedback and while watching the lesson on the video tape with the directions of the researcher as well as colleagues in the light of the observation form and after giving feedback to each student in the group in the discussion session asked the researcher Each student re - planning a second lesson.

5 - Each student re - planning the lesson and re - teaching for the second time in the mini - seminar and then received feedback again.

6- The researcher met with the students of the group at the end of the first and second training stage in order to evaluate and learn about the pros and cons.

\section{3 - The evaluation phase of the training program:}

The researcher conducted a post-test writing skill and applied both individually and after the end of the period of training the students on the skill of writing and was asked to each student from the experimental group to provide a lesson on the skill of teaching and carried out all the lessons in the presence of all students and evaluated the performance of students by the researcher using my form Observation.

\section{4- Final field evaluation stage:}

After completing the research procedures and experience, the students of Ajloun University / Fourth Year go to practical training in primary schools and here the researcher followed them and observed them in the schools where they applied. The researcher took the names of the students and the schools that they will apply from the college. Trainees in their schools and entering the classroom with them and sit in the back seats to record their performance on the note form of writing skills.

\section{A survey and resultsdiscussion}

First: Resultssurvey:

The first hypothesis:

There was no statistically significant difference between the average pre-test and post-test scores in the performance of the research group for writing skill. To investigate this hypothesis, the researcher used the appropriate t-test to compare the scores of the sample students in the pre-test and post-test. The mean for the tribal test (41.7500) and the standard deviation (4.480). The post-test was the arithmetic mean (65.6667) and the standard deviation (5.4495) for writing skill. When these data were processed statistically using T-test, the results were as listed in Table (2) below:

Table (2)

Results (t-test) in knowing the difference between tribal and post-test.

\begin{tabular}{|c|c|c|c|c|c|}
\hline The group & number & mean & $\begin{array}{c}\text { Standard } \\
\text { deviation }\end{array}$ & \multicolumn{2}{|c|}{ T value } \\
\hline $\begin{array}{c}\text { The difference between the two tests } \\
\text { grades }\end{array}$ & 12 & 25.9167 & 5.6532 & calculated & tabled \\
\cline { 4 - 6 } & & 12.453 & $4.201 *$ \\
\hline
\end{tabular}

* Table T value below the level of significance (0.05) and degree of freedom (11).

Note from Table (2) above shows that the calculated T value (12.453) is higher than the tabular value of (4.201). Thus rejecting the zero hypothesis. It is clear from the data that the rejection was in favor of the post-test.

The second hypothesis:

There was no statistically significant difference between the average of the post-test and field tests in the performance of the research group for writing skill. To achieve this hypothesis, the researcher used the appropriate t-test to compare the scores of the sample students in the post and field tests. The mean for the posttest (65.6667) and the standard deviation (5.4495). The field test was the arithmetic mean (67.5833) and the standard deviation (17.040) for writing skill. 
Table (3)

Results (t-test) in knowing the difference between the post and field tests.

\begin{tabular}{|c|c|c|c|c|c|}
\hline group & number & mean & $\begin{array}{c}\text { Standard } \\
\text { deviation }\end{array}$ & \multicolumn{2}{|c|}{ T-VALUE } \\
\hline $\begin{array}{c}\text { The difference between the two } \\
\text { tests grades }\end{array}$ & 12 & 1.9167 & 4.3161 & calculated & tabled \\
\cline { 4 - 6 } & & $2.201 *$ & 1.538 \\
\hline
\end{tabular}

* Table T value below the level of significance (0.05) and degree of freedom (11).

From Table 3 above, it is clear that the calculated $T$ value (1.538) is less than the numerical value of (2.201). Thus accepting the zero hypothesis. This is because the averages were close.

\section{Second:Results discussion:}

The results of the study showed that the grades obtained by the students / sample in the post-test were higher than the pre-test scores. The researcher attributed the reason to the effectiveness of the training program and its obvious impact on the development of skill among special education students. In observing the results of the sub-skills of writing skills, the researcher found that the skill that obtained the highest percentage $(96.66 \%)$ was to teach the pupils to write in clear handwriting and facilitate reading with the commitment to write on the same line of paper, a necessary skill that the teacher must learn because students in The early stages of education often have a vague line with their lack of commitment to writing in a straight line, but a gradual line from top to bottom or vice versa.

As well as teaching the students and alert them to the importance of the points on the characters and not neglected because without it the letter is incomplete and unclear and teach the pupils how to use punctuation in their writings, and the numbering means the placement of special marks in writing (such as point and fares) to divide the parts of the sentence and to separate sentences and distinguish them from each other and to appoint Endowments, followed by the skill of teaching pupils to distinguish between the images of the letters of the first E, E, E, intermediate, third, and fourth. As well as teaching pupils to distinguish between images of similar characters and all these skills got $90 \%$. The skill of teaching students how to draw the intensity of drawing correctly in the different positions of the word has got the proportion (85\%).

And to alert the pupils to the correct way to reduce the pen, which is one of the most important written skills and the first is to help the child to get used to keeping the pen and move it correctly, which got the proportion of $(86.66 \%)$.

Teaching the students how to arrange the letters of words and sections correctly when writing, and also to draw the teacher to look at the starting point when writing the character and the way to write it as well as teaching students to distinguish between the writing of $\mathrm{T}$ and open tethered to have got $(83.32 \%)$.

And also teaching the pupils how to draw the letters in a correct and complete way, as if they got a percentage $(75 \%)$.

As well as teaching students how to write useful sentences about a situation and that students know how to write letters and numbers correctly and avoid the reversal when writing (3) it has got the average (65\%).

The skill of teaching students how to complete writing a story or news requires an addition has got $60 \%$.

All these skills are necessary and must be mastered by the students / teachers when teaching students the skill of writing. This skill has achieved a high percentage in the post and field tests after the end of the training program, which indicates the effectiveness of this program and its obvious impact on students / teachers.

The skills obtained low rate provided that the students were taught how to complete sentences or incomplete sentences in words inspired by the context, which received $(58.32 \%)$.

This may be due to the way in which the lesson or the way in which the lesson was presented to demonstrate the effectiveness of the training program but less than other skills.

\section{Second: Recommendations:}

In light of the researchresults, the researcher recommends the following:

1 - Emphasize the importance of the need for practical training of teaching skills before entering primary school in special education classes.

2 - Training courses to strengthen teachers of special education during the summer vacation.

3 - The need to pay attention to teaching methods for teachers of special education and work to improve them.

4 - Increase the interest in the training of teachers of special education on teaching skills.

5 - Interest in providing programs for the preparation and training of special education teachers within the programs of Ajloun University College of Applied University of Balqa to prepare and qualify crews specialized in the field of special education.

\section{References}

1. Al-Khataibeh and others, (2004), the classroom interaction, Dar Al-Shorouk, Amman-Jordan.

2. Abadi, Haifa Abdurrahman Ibrahim, (2004). The use of the method of repetition and illustrations in the adaptive behavior of the students of special education and their achievement in general science, Faculty of 
Education, Yarmouk University. unpublished MA thesis.

3. Abdul Rahim, Fathi al-Sayed (1990), the psychology of children and special strategies of special education, Dar Al-Qalam, Kuwait.

4. Al Rousan, Farouk (2004), studies and research in special education, edition1, Dar al-Fikr, Amman - Jordan

5. Al-Zaher and others, (2002), Principles of Measurement and Evaluation in Education, International Scientific House for Publishing and Distribution, Dar Al-Thaqafa for Publishing and Distribution, AmmanJordan.

6. Batayneh, Osama, (2004), assessment of the educational competencies of teachers of children with special needs in Northern Jordan, Journal of the Union of Arab Universities for Education and Psychology, no. (1), Syria, (pp. 31-49).

7. Bloom, Benjamin and others, (1983), Assessment of Collective or Formative Student Education, Mohammed Al-Mufti and Others, Dar Makirohil, Cairo.

8. Carr, Stetmati, (2001), Unusual Children (Their Psychology and Education), Al-Resala Foundation, Lebanon.

9. Freeman , F,S (1962) "Theory And Practice of psychological Testing" Newyork , (2004), Evaluation of Educational Competencies of Teachers of Children with Special Needs in Northern Jordan, Journal of the Union of Arab Universities for Education and Psychology .

10. Haroon, Saleh Abdullah, (1995), Survey of the views of the students of the Department of Special Education at King Saud University on the degree of their acquisition of the teaching competencies necessary to teach people with special needs in regular schools, King Saud University Journal of Educational Sciences.

11. Khatayba, Abdullah Mohammed and Ali AqeelAlimat, (2001), the appreciation of science teachers in Jordan for the level of their teaching skills in light of some variables, Damascus University Journal of Literature, Humanities and Educational Sciences,(Pp. 261-279).

12. Odeh, Ahmed Suleiman and Mufti Hassan Malkawi, (2014), Fundamentals of Scientific Research in Education and Human Sciences, edition 1, Al Manar Office, Zarqa.

13. Smadi, Jamil and Tayseer Al Nahar (2001), Level of Mastery of Special Education Teachers in the United Arab Emirates for Skills of Effective Education, Journal of Educational Research Center, Qatar University, No. (19), pp. 193-216. 